\title{
Constraints Perceived by Psychiatrists Working in Community Mental Health Services. Development and Pilot Study of a Novel Instrument
}

\author{
Gian Maria Galeazzi, M.D., Ph.D. \\ Andrew Mackinnon, Ph.D. \\ Paolo Curci, M.D.
}

\begin{abstract}
An inventory of institutional constraints perceived as limiting therapeutic choices was developed and completed by psychiatrists working in Italian public mental health services. Constraints considered most limiting were social and institutional pressures toward social control, violence risk assessment and prevention, and lack of control over workload. The total mean score of the perceived constraints instrument was significantly negatively correlated with ratings of perceived freedom in therapeutic choices and with overall job satisfaction. Reliability was good (alpha $=0.85$ ). Addressing perceived constraints may result in more choice options to reach therapeutic goals in a collaborative framework with patients, and improve job satisfaction.
\end{abstract}

KEY WORDS: community mental health services; therapeutic freedom; perceived coercion; job satisfaction.

Gian Maria Galeazzi is affiliated with the Newham Rehabilitation and Recovery Team, East London and the City University Mental Health Trust, London, UK.

Gian Maria Galeazzi and Paolo Curci are affiliated with the University of Modena and Reggio Emilia, Modena, Italy.

Andrew Mackinnon is affiliated with the Centre for Mental Health Research, Australian National University, Canberra, Australia.

Address correspondence to Gian Maria Galeazzi, M.D., Ph.D., Department of Neuroscience TCR, Section of Psychiatry, University of Modena and Reggio Emilia, Via del Pozzo, 71, 41100, Modena, Italy; e-mails: galeazzi@unimore.it; gian.galeazzi@elcmht.nhs.uk. 


\section{INTRODUCTION}

Mental health service research has demonstrated that users perceive various types of pressures in their relationships with treating agencies. The concept of perceived coercion and its operational measurement has recently attracted significant research interest and has helped elucidate important aspects of the interaction between services and users. The means by which pressures towards treatment are manifest vary, ranging from overt coercion to more subtle forms. Pressures come from a number of different sources such as family, friends, police officers and clinicians (Abderhalden, Hahn, Bonner, \& Galeazzi, 2006). The study and reduction of coercion related to treatment has important ethical implications and may have a positive impact on relevant outcomes. However, the results of studies, which have attempted to test the hypothesis that lower perceived coercion is related to better outcomes have not been compelling thus far (Rain et al., 2003; Bindman et al., 2005).

In contrast to the perception of coercion by users, little attention has been paid to the coercion and constraints perceived by clinicians to impact their therapeutic choices with patients. Such issues emerge only indirectly in the literature on burnout, managed care, and the legal liability of clinicians (Oberlander, 1990; Schlesinger, Dorwart, \& Epstein, 1996; Simon, 1998). Only very recently has the idea been proposed of measure coercion perceived by psychiatrists (rather than by clients) in their treatment choices. For example, the MacArthur Coercion Scale (Gardner et al., 1993) has been administered to doctors admitting patients to hospital regarding the doctors' perception of extra-clinical pressures on their decisions to admit (Sheehan \& Burns, 2006). About a third of professionals surveyed felt that their decision to admit had been influenced by extra-clinical factors.

Responding to the dearth of research in this evidently important area, this study sought to:

1. identify which institutional constraints are felt by psychiatrists working in public psychiatric services to impact their freedom of therapeutic choice with clients;

2. construct and pilot-test an instrument designed to measure these perceived constraints and determine the extent to which the items could be used as a scale;

3. determine whether perceived constraints-as measured-were correlated, not only with global ratings of therapeutic freedom, but also with job satisfaction in the professionals concerned. 


\section{METHODS}

\section{Instrument}

A list of perceived constraints relating to institutional policies and structures was developed from a focus group of eight psychiatrists working in public psychiatric services in the Northern Italian Province of Modena. Common themes were identified and summarized into 19 items. These were incorporated into a questionnaire-the Constraints Perceived by Psychiatrists Inventory (CPPI; available on request from. the corresponding Author). The CPPI asks respondents to rate how much each factor was felt as limiting the respondent's therapeutic choices with patients in everyday work. A Likert type response scale is used, ranging from 1 ('not at all') to 5 ('a great deal').

The questionnaire also asked about respondents' job satisfaction (using a visual analogue scale from 0 , minimum satisfaction to 10 , maximum satisfaction) and about their perceived extent of freedom of therapeutic choice with their patients (from 0 , minimum freedom to 10 , maximum freedom). Therapeutic freedom was defined as the absence of extra-clinical influences on therapeutic decision-making with patients. Socio-demographic and professional data were also solicited.

\section{Participants}

The questionnaire was distributed to 96 psychiatrists working in the public psychiatric services in the Emilia Romagna Region. Fifty-two questionnaires were collected; 50 were analyzable (valid response rate $52 \%$ ). Twenty-one $(42 \%$ ) participants were female; mean age was 46.7 (sd 7.1); mean years of experience working with psychiatric patients was 16.9 ( $\mathrm{sd} \mathrm{8.0);} \mathrm{the} \mathrm{principal} \mathrm{setting} \mathrm{of} \mathrm{work} \mathrm{for} \mathrm{the} \mathrm{majority} \mathrm{of} \mathrm{respondents} \mathrm{was} \mathrm{an}$ Outpatient Community Mental Health Centre $(n=33,66 \%$ ); fifteen (30\%) worked in Acute Adult Inpatient Units, and two worked mainly in residential rehabilitation facilities.

\section{Analysis}

Descriptive statistics and Pearson correlations are reported. Reliability of the scale was indexed by Cronbach's alpha. Analyses were undertaken with SPSS version 13.0.

All authors certify responsibility for this paper and declare no conflict of interest related to it.

\section{RESULTS}

The items of the perceived constraint scale were well-accepted by participants. The full range of response categories were used for the majority of items. Table 1 shows means and standard deviations of ratings given to each of the 19 items.

Mean total score on the constraint scale was 53.8 (sd 10.6). Overall reliability was good (Cronbach's alpha $=0.85$ ) and corrected item-total correlations were substantial, ranging 0.11 to 0.70 (see Table 1). Only 


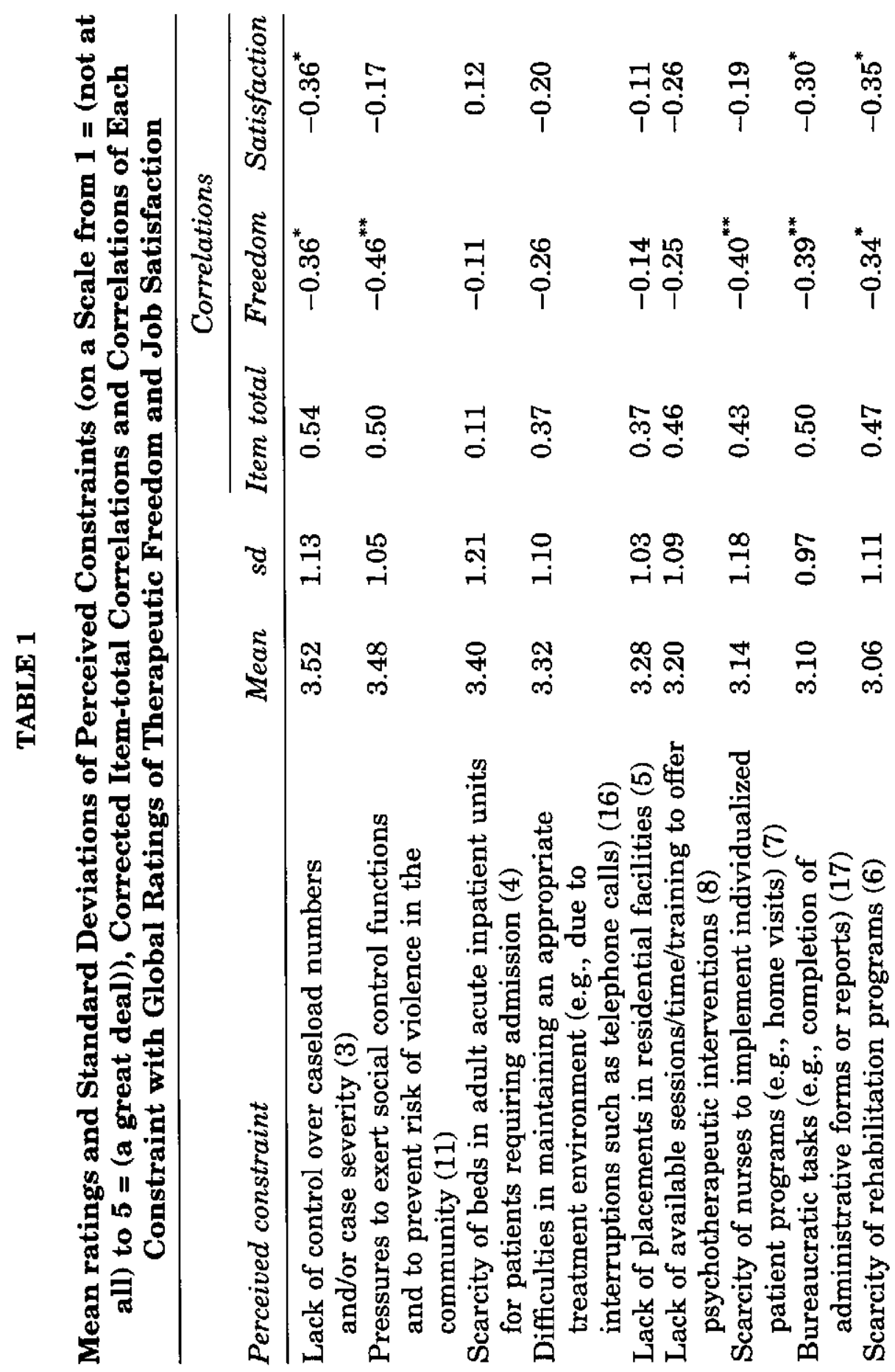




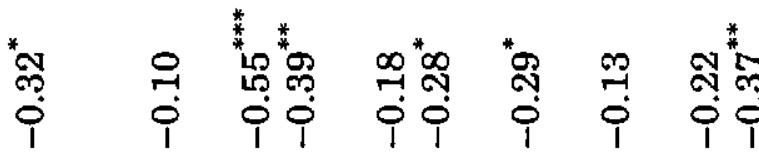

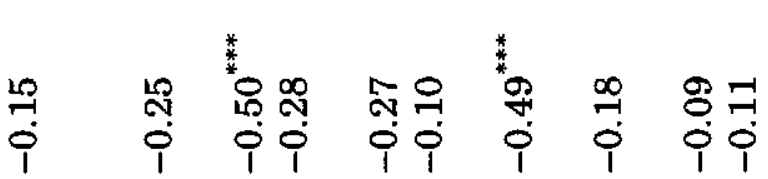

ஸั

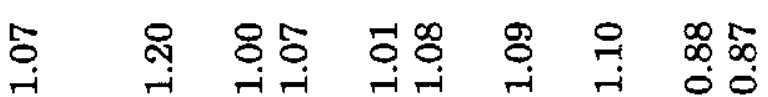

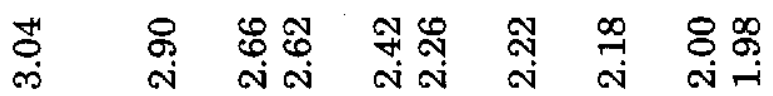

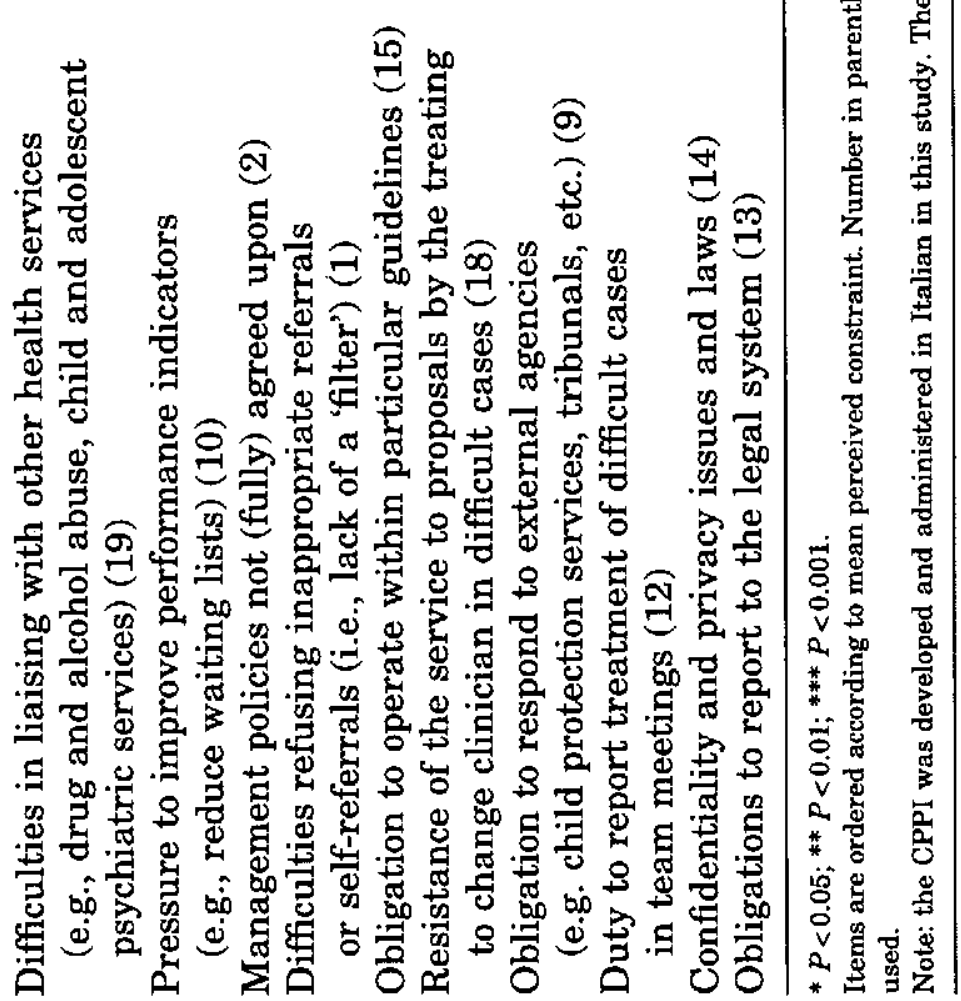


one item ('scarcity of beds in adult acute inpatients units') had an itemtotal correlation substantially below 0.3. Despite its minor contribution to the scale, this item was retained given the early stage of development of this instrument. Mean rating of job satisfaction was 6.5 (sd 1.7), mean global rating of perception of freedom in therapeutic choices with patients was 6.4 (sd. 1.9). These two scores were substantially and significantly correlated $(r=0.56, P<.001)$.

No significant differences in CPPI total score were found between males and females or between psychiatrists working in community centres and those based in inpatient units $[\mathrm{t}(48)=2.50, P=0.279$; and $\mathrm{t}(48)=1.76, P=0.86$ respectively]. Correlations of the CPPI with age and with years working in mental health were not significant $(r=0.13$, $P=0.443$; and $r=-0.19, P=.228$ respectively). The CPPI was substantially negatively correlated with respondents' global rating of job satisfaction $(r=-0.46, P<.001)$ and perception of freedom in therapeutic choices $(r=-051, P<.001)$.

Table 1 reveals that correlations between ratings of therapeutic freedom and individual items of the constraint instrument ranged from negligible to moderate in size. Aspects of perceived constraint correlating substantially with therapeutic freedom encompassed a variety of facets of the psychiatrists' roles. These included disagreement with management policies $(r=-0.50)$; duty to respond to external agencies $(r=-0.49)$; pressures to exert a social control function $(r=-0.46)$. Lower but significant correlations existed for bureaucracy, lack of nurses to implement individualized programs, lack of control over workload, scarcity of rehabilitation programs (range $r=-0.34$ to -0.39 ).

Constraint items least related to perceived therapeutic freedom concerned confidentiality, privacy and legal issues, and changes in doctor for difficult cases (all less than $r=0.11$, n.s.).

Similar correlations were found between global job satisfactions and perceived constraints (see Table 1). Like therapeutic freedom, job satisfaction was substantially related to disagreement with management policies $(r=-0.55)$ and lack of control over workload $(r=-0.36)$ and scarcity of rehabilitation programs $(r=-0.35)$. It was also related to lack of a filter for new referrals $(r=-0.39)$; duty of reporting patients to the legal system $(r=-0.37)$ and difficulties in networking with other health services $(r=-0.32)$. 


\section{DISCUSSION}

This study shows that it is both feasible and desirable to identify different kinds of institutional restraints which psychiatrists working in public services perceive as limiting their therapeutic freedom. These constraints may be assessed with a simple instrument, whose construct and face validity (established by virtue of the source of the items) is reinforced by a high level of reliability. Ratings on the CPPI were related not only to respondents' global perceptions of freedom in therapeutic choices but also to their job satisfaction, further supporting the validity of the inventory.

This is one of the first studies to consider perceived coercion of clinicians in a systematic research context and to use the association with job satisfaction to support its construct validity. The instrument we developed to measure perceived constraints may be further validated in future studies in other settings or modified to reflect the specific context to be explored. Even though the findings of the present study cannot, in principle, be automatically generalized to differently structured and organized health systems, the application of the same method in different settings may reveal key similarities and could lead to the delineation and differentiation of universally perceived and more system-specific constraints. A similar approach has been suggested by Priebe and colleagues in studying burnout and job-satisfaction in mental health professionals in London and Berlin (Priebe, Fakhouri, Hoffmann, \& Powell, 2005).

Our findings confirm the difficulties that public psychiatric services in the service studied face in fulfilling growing and at times conflicting requests coming from users, local communities and institutions (Angelozzi et al., 2005; Eikelmann, Richter, \& Reker, 2005; Rey, Walter, \& Giuffrida, 2004). The issue of pressure towards the adoption of a stricter and more efficient social control function-especially concerning the risk of violence from users in the community-is causing growing alarm among mental health professionals (Appelbaum, 2003; Allevi, Salvi, \& Ruggeri, 2006). In our sample these pressures ranked amongst the highest perceived constraints. The widely adopted managed care model of services (and associated reduction in budgets), quality assurance policies, and the obligation to operate within particular guidelines and specific procedures have also been cited as possible factors limiting clinicians' freedom of therapeutic choice with their patients (Schlesinger et al., 1996). In a recent review of current issues 
surrounding the role of community psychiatrist Rosen (2006) expressed concerns about the pressures of the "law and order/security agenda" and of the "economy of scale agenda" imposed on mental health professionals by health departments and mental health administrations. Our study provides empirical support to these concerns, showing that these pressures and constraints amount to a demonstrable lack of autonomy in the therapeutic choices dependent on extra-clinical factors as perceived by clinicians. These issues bear a close resemblance to the concept of coercion of treatment perceived by users. Lack of autonomy and of choice are, in fact, an integral part of the perceived coercion concept.

Other types of perceived constraints ranking highly in the present study centre on the availability of resources (such as scarcity of beds in different types of facilities), walk-in policies for accessing services (with resulting difficulties in filtering access and limiting workload), management goals of achieving better results on performance indicators, application of guidelines and the fulfilling of bureaucratic requests.

The relevance of these constraints to quality of work is confirmed by the fact that they are significantly related to job satisfaction and to global ratings of therapeutic freedom. Perception of a high workload and of team conflicts (especially those with clinical and management directors) as negatively impacting on job morale, confirms previous research conducted in the same geographical area (Galeazzi, Delmonte, Fakhoury, \& Priebe, 2004). Lack of beds was mentioned as the most dissatisfying aspect of public psychiatric practice in a recent survey of Australian psychiatrists (Rey et al., 2004). Other research shows that decreasing clinical autonomy and inability to obtain services for patients are important factors in doctors' dissatisfaction (Landon, Reschovsky, \& Blumenthal, 2003). A correlation between perceived low autonomy and low job satisfaction has also been previously highlighted by Reid et al. (1999) in English professionals and by Gigantesco, Picardi, Chiaia, Balbi, \& Morosini (2003) in Italian psychiatrists.

In this study, correlations between explored perceived constraints with job satisfaction and with perceived level of freedom in therapeutic choices showed partial but not complete overlap. This supports the view that the factors which emerged in the focus group do not merely tap issues impacting on job dissatisfaction. Considering the current emphasis on the importance of the adoption of a collaborative model between users and mental health professionals in therapeutic choices (Adams \& Drake, 2006), extra-clinical constraints acting on the 
professionals and limiting their therapeutic freedom, if not addressed, could become a critical obstacle to the implementation of this approach.

Among the limitations of the present study, we acknowledge small sample size, moderate response rate, and lack of established measures of perceived constraints against which to test concurrent validity of the instrument developed. However, the latter problem partially motivated construction of our questionnaire.

In developing the CPPI, we were aware that not all of the listed perceived constraints can necessarily be considered independent of the way clinicians work. However, at this stage of this research, we were interested in the subjective experience of professionals. The availability of a simple assessment tool, which provides a reliable method of ascertaining the extent to which clinician feel particular aspects of their work settings limit their treatment choices, is relevant in terms of informing management policy in psychiatric services and in terms of future research studies.

Further research should investigate the structure of the CPPI in larger samples with a view to determining the dimensions of perceived constraint. This leads logically to the investigation of similarities and differences between services and between different mental healthcare professions. The relationship and direction of associations between job satisfaction, burnout and perceived constraints merits further exploration. In the context of efforts aiming at improving job morale, measurement and analysis of perceived constraints upon professionals, such as reported here, may be helpful in identifying possible targets for intervention. Ultimately, evaluation of the relationship of degree and type of constraints perceived by professionals to patient outcomes could prove a valuable application of this instrument.

\section{ACKNOWLEDGMENTS}

Dr. Gaddomaria Grassi (Reggio Emilia, Italy), Dr. Andrea Melella (Cesena, Italy), and Prof. Marco Rigatelli (Modena, Italy) are acknowledged and thanked for having allowed this research in their respective Community Mental Health Services. We also thank Prof. Patrick Callaghan for helpful comments on an earlier draft of the manuscript. 


\section{REFERENCES}

Abderhalden, C., Hahn, S., Bonner, Y. D., \& Galeazzi, G. M. (2006). Users' Perceptions and Views on Violence and Coercion in Mental Health. In D. R. Richter Whittington (Ed.), Violence in mental health settings. Causes, consequences, management Springer, NewYork.

Adams, J. R., \& Drake, R. E. (2006). Shared decision-making and Evidence-Based Practice. Community Mental Health Journal, 42, 87-105.

Allevi, L., Salvi, G., \& Ruggeri, M. (2006). Quality of mental health services: a self audit in the South Verona mental health service. Epidemiologia e Psichiatria Sociale, 15, 138-147.

Angelozzi, A., Bassi, M., Cappellari, L., Favaretto, G, Ferrannini, L., Fioritti, A., Munizza, C., Peloso, P., Perozziello, F., Pirfo, E., Rossi, I., Scapati, F., \& Zuccolin, M. (2005). Documento sullo stato e sulle prospettive della psichiatria italiana. [About the situation and perspectives of Italian Psychiatry, in Italian]. Psicoterapia e Scienze Umane, 39, 293-306.

Appelbaum, P. S. (2003). Law and Psychiatry: Dangerous persons, moral panic, and the uses of psychiatry. Psychiatric Services, 54, 441-442.

Bindman, J., Reid, Y., Szmukler, G., Tiller, J., Thornicroft, G., \& Leese, M. (2005). Perceived coercion at admission to psychiatric hospital and engagement with follow-up: a cohort study. Social Psychiatry and Psychiatric Epidemiology, 40, 160-166.

Eikelmann, B., Richter, D., \& Reker, T, (2005). Pro und Kontra: Gemeindepsychiatrie in der Krise? Pro [For and against: a crisis of community psychiatry? For, in German]. Psychiatrische Praxis, 32, 269-270.

Galeazzi, G. M., Delmonte, S., Fakhoury, W., \& Priebe, S. (2004). Morale of mental health professionals in Community Mental Health Services of a Northern Italian Province. Epidemiologia e Psichiatria Sociale, 13, 191-197.

Gardner, W., Hoge, S., Bennett, N., Roth, L. H., Lidz, C. W., Monahan, J., \& Mulvey, E. P. (1993). Two scales for measuring patients' perceptions of coercion during mental hospital admission. Behavioral Sciences and the Law, 11, 307-321.

Gigantesco, A., Picardi, A., Chiaia, E., Balbi, A., \& Morosini, P. (2003). Job satisfaction among mental health professionals in Rome, Italy. Community Mental Health Journal, 39, 349-355.

Landon, B. E., Reschovsky, J., \& Blumenthal, D. (2003). Changes in career satisfaction among primary care and specialist physicians, 1997-2001. JAMA, 289, 442-449.

Oberlander, L. B. (1990). Work satisfaction among community-based mental health service providers: The association between work environment and work satisfaction. Community Mental Health Journal, 26, 517-532.

Priebe, S., Fakhouri, W. K. H., Hoffmann, K., \& Powell, R. A. (2005). Morale and job perception of community mental health professionals in Berlin and London. Social Psychiatry and Psy. chiatric Epidemiology, 40, 223-232.

Rain, S. D., Williams, V. F., Robbins, C. P., Monahan, J., Steadman, H. J., \& Vesselinov, R. (2003). Perceived coercion at hospital admission and adherence to mental health treatment after discharge. Psychiatric Services, 54, 103-105.

Reid, Y., Johnson, S., Morant, N., Kuipers, E., Szmukler, G., Thornicroft, G., Bebbington, P., \& Prosser, D. (1999). Explanations for stress and satisfaction in mental health professionals: a qualitative study. Social Psychiatry and Psychiatric Epidemiology, 34, 301-308.

Rey, J. M., Walter, G., \& Giuffrida, M. (2004). Australian psychiatrists today: proud of their profession but stressed and apprehensive about the future. Australian and New Zealand Journal of Psychiatry, 38, 105-110.

Rosen, A. (2006). The community psychiatrist of the future. Current Opinion in Psychiatry, 19, 380-388.

Schlesinger, M., Dorwart, R. A., \& Epstein, S. S. (1996). Managed care constraints on psychiatrists' hospital practices: bargaining power and professional autonomy. American Journal of Psychiatry, 153, 256-260.

Sheehan, K. A., Burns, T. Non-medical influences on psychiatric hospitalization. Abstract Book of the 2006 American Psychiatric Association Meeting, May 20-25, Toronto, Canada.

Simon, R. (1998). Psychiatrists' duties in discharging sicker and potentially violent inpatients in the managed care era. Psychiatric Services, 49, 62-67. 